\title{
Saúde mental, direitos humanos e sistema penal: reinventando a extensão em tempos pandêmicos desmedidos
}

\author{
Mental health, human rights and penal system: \\ reinventing extension in desmedited pandemic times
}

\author{
Moises Romanini ${ }^{a}$ \\ (iD) https://orcid.org/0000-0003-3288-4763 \\ E-mail:mromaniniðgmail.com \\ Simone Mainieri Paulon ${ }^{\mathrm{a}}$ \\ (iD) https://orcid.org/0000-0002-0387-1595 \\ E-mail:simonepaulonळgmail.com \\ Dário Frederico Pasche \\ (D) https://orcid.org/0000-0001-7161-8607 \\ E-mail:dario.pascheळgmail.com \\ Moysés da Fontoura Pinto Neto ${ }^{c}$ \\ (iD) https://orcid.org/0000-0003-4785-9691 \\ E-mail:moysespintoneto®gmail.com \\ anniversidade Federal do Rio Grande do Sul, Instituto de \\ Psicologia, Programa de Pós-Graduação em Psicologia Social \\ e Institucional. Porto Alegre, RS, Brasil. \\ bUniversidade Federal do Rio Grande do Sul, Escola de \\ Enfermagem, Programas de Pós-Graduação em Psicologia Social \\ e Institucional e em Saúde Coletiva. Porto Alegre, RS, Brasil. \\ 'Universidade Luterana do Brasil, Programa de Pós-Graduação \\ em Educação. Canoas, RS, Brasil.
}

\section{Correspondência}

Moises Romanini

Rua Ramiro Barcelos, 2600. Porto Alegre, RS, Brasil. CEP 90035-003.

\section{Resumo}

Partindo de uma problematização acerca da noção de periculosidade e do dispositivo da medida de segurança, este relato tem como objetivo trazer ao debate experiências de um programa de extensão pautado nas relações entre saúde mental, direitos humanos e sistema penal. Com a pandemia do novo coronavírus, as ações do programa foram reestruturadas e passaram a ter como foco a formação-intervenção de estudantes e profissionais. Com base na perspectiva metodológica da pesquisaintervenção, a extensão promoveu um ciclo de diálogos com entrevistas de profissionais que trabalham o tema-foco do programa. Além disso, realizou a construção de um observatório, com um repositório on-line dispondo de materiais sobre o tema e ações do programa. Por fim, organizou um curso, na modalidade a distância, sobre saúde mental, direitos humanos e sistema penal. O fluxo de acessos aos conteúdos publicados e, principalmente, a quantidade de inscritos no curso, que atraiu profissionais e estudantes majoritariamente das áreas de direito, psicologia e serviço social, indicam o interesse e a pertinência de ações que visam a desinstitucionalização das medidas de segurança, um tema necessário para a sustentação do processo de reforma psiquiátrica e defesa dos direitos humanos no país.

Palavras-chave: Saúde Mental; Direitos Humanos; Sistema Penal; Medida de Segurança; Periculosidade. 
Abstract

From a problematization of the notion of dangerousness and the security measure device, this manuscript aims to bring to light experiences of an extension program based on the association between mental health, human rights, and the penal system. With the novel coronavirus pandemic, the program actions were restructured, now focusing on the training-intervention of students and professionals. Based on the methodological perspective of research-intervention, the extension promoted a cycle of dialogues with interviews of professionals who work with the Program's focus. Moreover, it also developed an observatory with an online repository including materials on the Program's theme and actions and organized an online learning course on mental health, human rights, and the penal system. The access to the published content and the number of students and professionals enrolled in the course, mostly from the fields of law, psychology, and social work, indicate the interest and pertinence of actions aimed at the deinstitutionalization of security measures as a necessary theme to sustain psychiatric reform and human rights defense in the country.

Keywords: Mental Health; Human Rights; Penal System; Security Measure; Dangerousness.
Introdução - problematizações sobre a noção de periculosidade e o dispositivo da medida de segurança

Em meados de junho de 2020, o Ministério da Saúde publicou uma portaria extinguindo o serviço da saúde prisional realizado por Equipes de Avaliação e Acompanhamento de Medidas Terapêuticas Aplicáveis à Pessoa com Transtorno Mental em Conflito com a Lei (EAP). Esse serviço, iniciado em 2014, preconiza o acompanhamento de pessoas em cumprimento de medidas de segurança ou à espera de um exame que lhes ateste a existência de transtornos mentais (Brasil, 2014). Diante das inúmeras críticas e pressões de diversas instâncias (movimentos sociais de saúde mental e direitos humanos, Colégio Nacional de Defensores Públicos Gerais, Conselho Nacional de Justiça, Conselho Nacional de Saúde, Mecanismo Nacional de Prevenção e Combate à Tortura, dentre outros) quanto aos efeitos desastrosos que teria a extinção das EAP, foi revogada a portaria (Conselho Federal de Psicologia, 2020a; Martins, 2020). Entretanto, o serviço se mantém com cortes orçamentários e diminuição significativa de profissionais da saúde mental no contexto da Política Nacional de Atenção Integral à Saúde da Pessoa Privada de Liberdade no Sistema Prisional (PNAISP) (Conselho Federal de Psicologia, 2020b).

Esse nos parece ser mais um dos efeitos dos movimentos contrarreformistas e de remanicomialização do cuidado em saúde mental, a exemplo da Nota Técnica n ${ }^{0}$ 11/2019 (Brasil, 2019), que propõe mudanças na Política Nacional de Saúde Mental e nas Diretrizes da Política Nacional sobre Drogas, incluindo, entre os equipamentos que compõem a Rede de Atenção Psicossocial (RAPS), serviços retrógrados como hospital-dia, ambulatório multiprofissional, comunidades terapêuticas de caráter asilar e, ironicamente, até o hospital psiquiátrico entre os serviços que a Lei 10.216 (Brasil, 2001) afirma como "substitutivos" a ele mesmo. Tais inclusões são justificadas pelo questionável argumento de que todos os serviços são igualmente importantes e devem ser incentivados, ampliados e fortalecidos. Buscando neutralizar 
o ataque ao modelo de atenção psicossocial e à luta antimanicomial, a nota técnica utiliza-se de expressões como "rede harmônica e complementar" e da ideia de que todos os serviços são importantes, contrapondo-se à legislação vigente que outorga o lugar/função de serviços substitutivos aos Centros de Atenção Psicossocial (CAPS). Tal medida, todavia, torna-se uma forma de desmontar os avanços conquistados ao longo das últimas décadas pelo movimento da reforma psiquiátrica.

Sabemos que, historicamente, o hospital psiquiátrico configurou-se como o único recurso de "tratamento" aos ditos "loucos". Por volta da década de 1970, a partir de denúncias de maustratos e violação de direitos humanos, bem como de uma reorientação das instituições psiquiátricas e da proposição de um modelo de atenção de base comunitária oposto ao modelo hospitalocêntrico, ficou evidente que o cuidado em saúde mental era caracterizado e localizado em um lugar de violência, silenciamento, morte, segregação e exclusão social.

No decorrer do século XIX, tanto na Europa quanto no Brasil, métodos de repartição analítica do poder (Foucault, 1991) promoveram um conjunto de instituições e técnicas que visavam medir, controlar e corrigir os “anormais”, através de práticas de internamento em asilos, prisões e manicômios. Desde então, o cuidado às pessoas com transtornos mentais se tornou sinônimo de internação em hospitais psiquiátricos, isolando essas pessoas do convívio comunitário por períodos prolongados de reclusão, o que acarretou processos de estigmatização e exclusão social dessas pessoas (Paulon et al., 2017; Soares Filho; Bueno, 2016).

Por outro lado, a questão da desinstitucionalização da loucura no sistema penal traz o agravante do crime, em torno do qual os discursos jurídicos-penais e psiquiátricos se entrelaçam, no estabelecimento de redes causais entre a biografia do sujeito e sua sentença, produzindo o que Foucault (1991) chamou de "punição-correção". De um lado, a psiquiatria, que se viu diante da necessidade de ser reconhecida como uma modalidade de saber com o poder de atuar no campo da medicina através de ações de higiene mental e pública. De outro, o direito, organizado em torno dos saberes sobre o homem criminoso, que não se preocupava apenas com a correlação entre crime e pena para exercer sua função punitiva, mas sobretudo, com a natureza ou essência do criminoso.

O manicômio judiciário, portanto, foi produzido pela fusão entre manicômio e prisão, respaldados pelos saberes da psiquiatria e do direito, gerando os "hospitais-prisão" ou "prisões-hospital", caracterizados por serem, ao mesmo tempo, espaços prisionais-penitenciários e asilares-hospitalares (Carrara, 1998). A conexão entre esses domínios do saber e fazer - Saúde Mental e Justiça - provoca atitudes preconceituosas e criminalizadoras, gerando obstáculos para as práticas efetivas de saúde mental (Paulon et al., 2017; Soares Filho; Bueno, 2016; Tedesco, 2018). Essas dificuldades, por sua vez, invisibilizaram os pacientes judiciários, os loucos infratores, internados em instituições de caráter asilar que recebem pessoas com transtorno mental em conflito com a lei para o cumprimento de medidas de segurança (Barros-Brisset, 2010; Paulon et al., 2017; Tedesco, 2018). Neste sentido, como afirma Tedesco (2018, p. 85), precisamos "reconhecer que os avanços da Reforma Psiquiátrica não chegaram aos pacientes judiciários".

Além da história das formas de conceber e tratar a loucura, os manicômios judiciários revelam os diferentes movimentos da criminologia. Foi com a chamada virada paradigmática na Criminologia, produzida a partir das obras de Sutherland e Becker, que ocorreu um deslocamento do problema das causas do crime - pergunta etiológica - para os fatores de criminalização, entendendo o crime como efeito seletivo que elege, por razões de poder, dentre a imensa quantidade de pessoas que pratica crimes, aquelas que são os seus alvos preferenciais (Carvalho, 2010; Zaffaroni; Batista; Alagia; Slokar, 2003).

São os discursos criminológicos críticos que nos ajudam a entender que a parceria entre a psiquiatria e o direito incubou a concepção de indivíduo perigoso (Foucault, 2004) - a periculosidade. E a periculosidade, por sua vez, gestou o manicômio, filho desse casamento entre direito e psiquiatria. Tomando como ponto de partida a constituição do alienismo, que constrói um saber sobre a loucura que a considera irresponsável e perigosa, o dispositivo de controle-dominação da loucura, formado principalmente pelo saber psiquiátrico e pela justiça criminal, absolve o louco do crime, mas o interna 
valendo-se do argumento psiquiátrico-jurídico da doença-perigo (Foucault, 1991; 2004). Dessa forma, a atuação do direito penal e da psiquiatria, por meio do dispositivo da periculosidade, é respaldada institucionalmente como medida de segurança.

Como pondera Barros-Brisset (2011), passaramse cem anos de Pinel a Lombroso, e a exceção dos dementes tornou-se a regra de todos os que cometem atos infracionais. Para a autora, "é a ideia pineliana de um déficit moral intrínseco na loucura, o que faz dos loucos indivíduos intrinsecamente perigosos" (Barros-Brisset, 2011, p. 46). A periculosidade de pessoas com transtornos mentais, portanto, é concebida como a probabilidade que essas pessoas apresentam de cometerem atos violentos e/ou infracionais. O sistema e a legislação penais utilizam-se do binômio loucura-crime de forma explícita para justificar as sanções penais aplicadas às pessoas com transtornos mentais (Soares Filho; Bueno, 2016; Barros-Brisset, 2010).

Tais afirmações corroboram os achados do Censo realizado em 2011, quando a pesquisa, feita com a totalidade dos 26 Estabelecimentos de Custódia e Tratamento Psiquiátrico (ECTP) vigentes à época no Brasil, não encontrou qualquer correlação significativa entre os diagnósticos psiquiátricos e os crimes cometidos pelos internos. 0 resultado aponta para a centralidade que o dispositivo da periculosidade ganha nesse debate e, como afirma a pesquisadora que o coordenou, o quanto se trata de um conceito moral "[...] em permanente disputa entre os saberes penais e psiquiátricos" (Diniz, 2013, p. 15). É importante lembrar que, conforme Azevedo (1987) pontuou, a noção de loucura vinculada naturalmente à de periculosidade serviu ao controle urbano, internando e excluindo da sociedade os loucos, indigentes e "delinquentes". À luz dessa perspectiva, nota-se uma denúncia racista nesse paradigma e nessa forma de conceber a periculosidade, que construiu a noção de homem "naturalmente" perigoso colada biologicamente no fenótipo negro, sendo a medida de segurança uma imposição seletiva de corpos negros (Ramos, 2019; Magno; 2020).

Portanto, a concepção de periculosidade como essa marca permanente em pessoas com transtornos mentais em conflito com a lei tem como efeito o estabelecimento e a manutenção de penas-tratamento que mantém as pessoas enclausuradas por tempo indeterminado. Se não avançarmos no embate entre saúde mental e sistema penal, "indivíduos com transtorno mental em conflito com a lei permanecerão criminalizados e tutelados em regime informal de prisão perpétua, vítimas de um conjunto ineficiente de práticas asilares, punitivas e excessivamente medicamentosas" (Tedesco, 2018, p. 86).

Diante desse pressuposto que relaciona intrinsecamente a periculosidade à loucura, em nome da defesa social, o direito deveria desenvolver um mecanismo que tratasse desse indivíduo perigoso, excluindo-o da sociedade até que cessasse a sua periculosidade. Por isso, destaca Barros-Brisset (2011):

O nó entre defesa social e periculosidade criminal normatiza a parceria direito-psiquiatria, criando uma nova tecnologia de controle desses casos: a medida de segurança - uma precaução ao estado perigoso do indivíduo portador do déficit moral. Sua internação é por tempo indeterminado, e é assim até os dias de hoje. (Barros-Brisset, 2011, p. 47)

A medida de segurança é apresentada como uma possibilidade para os inimputáveis no Código Penal Brasileiro (Brasil, 2010). Após longo período de revisão do código, e, especificamente, com a reforma da Parte Geral de 1984, o louco infrator passou a ser vinculado ao conceito jurídico de inimputabilidade, expresso no artigo 26 do código: "é isento de pena o agente que, por doença mental ou desenvolvimento mental incompleto ou retardado, era ao tempo da ação ou da omissão inteiramente incapaz de entender o caráter ilícito do fato ou de determinar-se de acordo com esse entendimento". Ao ser considerado como inimputável ou semiimputável, ou seja, o sujeito não pode ser considerado responsável pelos seus atos infracionais, a pessoa com transtorno mental não recebe uma pena, mas uma medida de segurança. Sua sentença é a de um "tratamento", sendo juridicamente "absolvido" (Soares Filho; Bueno, 2016).

O tratamento imposto pela medida de segurança, a depender da sentença judicial, pode ser via internação ou por modo ambulatorial, até que se avalie a cessação da periculosidade. Dessa forma, 
"o tempo de cumprimento da medida de segurança é pautado pela periculosidade, como se fosse possível estabelecer-se alguma medida de valor, calculada em tempo de reclusão, para o grau de perigo que o sujeito impõe à sociedade" (Paulon et al., 2017, p. 359). Levando isso em conta, entendemos que a medida de segurança é um desafio ao movimento da Reforma Psiquiátrica brasileira, pois promove uma institucionalização de pessoas com transtornos mentais em conflito com a lei, condenando-as, na prática, a uma "prisão perpétua”. Soares Filho e Bueno (2016), ao analisarem essa dicotomia de posições entre o SUS e as normas de execução penal, sintetizam algumas características desse "tratamento" ofertado às pessoas com transtorno mental mantidas sob custódia pelo sistema penal

Modelo de tratamento determinado pela legislação criminal e não pela política pública de saúde; desinternação condicionada à cessação da periculosidade, sendo esta uma rara providência no sistema de justiça; internações perpétuas, sem indicação clínica para tal e independente da gravidade do delito; tratamento realizado na esfera da Justiça; escassa participação da rede pública de saúde/assistência social, com desresponsabilização da rede de saúde e assistência social na atenção a esta clientela; cronificação, reforço do estigma e institucionalização dos pacientes; perda irreversível de vínculos familiares e impossibilidade de retorno ao meio sociofamiliar; consumo de recursos públicos que deveriam estar sendo utilizados para financiar os serviços abertos, inclusivos e de base comunitária. (Soares Filho; Bueno, 2016, p. 2104)

Diante desse contexto e das discussões brevemente apresentadas, buscamos, neste relato, apresentar e refletir sobre as experiências do "Des'Medida-Saúde Mental e Direitos Humanos: por um acompanhar na rede", um Programa de Extensão desenvolvido desde 2012 na Universidade Federal do Rio Grande do Sul (UFRGS). O programa, que em sua proposta inicial tinha uma frente de trabalho mais assistencial, já vinha se reestruturando para assumir seu caráter mais formativo, o que se aprofundou diante das restrições impostas pela pandemia do novo coronavírus (SARS-CoV-2). Este relato de experiência, que busca também problematizar a medida de segurança e a noção de periculosidade por meio da discussão em torno dos processos de desinstitucionalização da loucura, está inscrito nesse contexto pandêmico, o qual nos convocou a reinventar as ações propostas em nosso programa de extensão.

\section{O programa "Des'Medida - Saúde Mental e Direitos Humanos: por um acompanhar na rede"}

O dispositivo do manicômio judiciário opera com a noção de periculosidade enquanto um instrumento que sustenta seu funcionamento e exerce controle sobre os corpos e desejos das pessoas com transtornos mentais em conflito com a lei. Esse dispositivo constitui e é constituído por discursos de construção social do louco perigoso que, em busca da defesa social e de uma consistência de um saber articulado em torno da loucura e do crime, lança os sujeitos para fora do mundo, "um não mundo para um não sujeito” (Paulon et al., 2017, p. 368).

Para enfrentar esse complexo contexto no qual estão inseridos os pacientes judiciários em nosso país e fortalecer o engajamento na luta antimanicomial e de defesa dos direitos humanos, foram implementados projetos e programas inovadores. Concebido como um projeto pioneiro no Brasil, o Programa de Atenção Integral ao Paciente Judiciário (PAI-PJ) é uma ação do Tribunal de Justiça do Estado de Minas Gerais que, alinhado à perspectiva da criminologia crítica e da reforma psiquiátrica, busca desconstruir e problematizar o dispositivo da medida de segurança e a noção naturalizada de periculosidade (Barros-Brisset, 2010, 2011).

O PAI-PJ vem implementando medidas, desde 1999, com o objetivo de subverter a lógica de exclusão e segregação, incentivando, por meio de apoio comunitário e redes de acolhimento, a inserção social de pessoas com transtornos mentais em conflito com a lei. Articula-se em parceria com diversos atores, como a rede pública de saúde de Minas Gerais, com os movimentos sociais de defesa dos direitos humanos em todo o estado. 0 programa oferece uma equipe 
multidisciplinar para avaliar o paciente judiciário e acompanhá-lo até a rede pública de saúde, visando a construção de um projeto terapêutico singular. Por meio do acompanhamento da aplicação das medidas de segurança, a equipe oferece subsídios para as decisões judiciais referentes aos incidentes de insanidade mental, com o intuito de promover o tratamento em saúde mental na rede pública de saúde.

No estado de Goiás, temos a experiência do Programa de Atenção Integral ao Louco Infrator (PAI-LI). O PAI-LI atua desde 2006 como responsável pela execução das medidas de segurança no estado, na perspectiva de evitar internações manicomiais e integrar os pacientes judiciários à rede de atenção psicossocial da região (Silva, 2010). Já no estado da Paraíba temos a significativa atuação do Grupo de Pesquisa e Extensão Loucura e Cidadania (LouCid). O LouCid atua desde 2012 realizando assessoria jurídica popular em direitos humanos e saúde mental, tendo como base os pressupostos da luta antimanicomial (Correia, 2020).

Por meio de ações como assistência jurídica, educação popular em direitos humanos, organização comunitária e participação popular, a assessoria jurídica popular desenvolvida pelo LouCid "se constitui como uma prática jurídica diferenciada dedicada à realização de ações para a garantia do acesso ao direito e à justiça a grupos subalternizados e movimentos ou grupos organizados em torno da luta por direitos” (Correia, 2020, p. 158). Cabe destacar a ação do LouCid com as "mulheres da justiça”, que busca visibilizar a situação jurídica através do acolhimento e mitigação do sofrimento mental de mulheres (Correia, 2020).

Pautado por essas mesmas diretrizes e debates, em 2012, uma equipe de professores da UFRGS, pesquisadores e militantes dos direitos humanos propôs uma parceria ao Poder Judiciário do Estado do Rio Grande do Sul e criou o programa de extensão "Des'Medida - Saúde Mental e Direitos Humanos: por um acompanhar na rede”. Inspirado no PAI-PJ, o programa Des'Medida propõe desmontar juridicamente o silêncio que submete o louco infrator aos porões dos manicômios judiciários, abrindo possibilidades para que possa emergir, desse processo, um sujeito de direitos (BarrosBrisset, 2011).
Estruturado como um programa de atenção intersetorial (Psicologia, Serviço Social e Direito) e interinstitucional (com professores vinculados a duas universidades em parceria com o Tribunal de Justiça), o trabalho junto à Vara de Execução e Penas Alternativas do TJ tinha como objetivo prestar assessoria ao Judiciário e às pessoas com transtornos mentais em conflito com a lei, com vistas à progressiva extinção do manicômio judiciário. Após a inserção do paciente judiciário no território, e com um tratamento singular de base comunitária, a assessoria era direcionada a juízes de primeira instância na aplicação e execução de sentenças cujos processos judiciais apresentavam indicativo de incidente de insanidade mental ou já estavam sentenciados com medidas de segurança.

Somando forças com as ações promovidas pelo PAI-PJ, sempre tivemos como foco a desinstitucionalização da medida de segurança. Daí a produção de sentido para o seu nome: a apóstrofe marca e destaca o prefixo "des" em relação à medida - des'medida, des'medir, des'institucionalizar: não se trata de mero processo de desospitalização, mas de desconstrução cultural, invisível e em boa parte inconsciente de valores e tradições arraigados socialmente. Trata-se de um posicionamento ético-político que defende o cuidado em liberdade e a desnaturalização do conceito de periculosidade, denunciando a medida de segurança como uma prisão perpétua legitimada pelo próprio sistema penal. A oferta de "um acompanhar na rede" àqueles e àquelas considerados(as) inimputáveis sinaliza uma valorização dos sujeitos e um estímulo à reconstrução de vínculos, mesmo nas situações ou contextos em que isso parece algo improvável.

Os efeitos subjetivos da aplicação da medida de segurança na vida do louco infrator não são menos danosos do que os observados no plano da violação dos direitos civis. Pois, como afirmam Paulon et al. (2017):

Se a reclusão às instituições totais com consequente submetimento do paciente judiciário a um modelo tutelar de atenção, quando não de maus-tratos e abandono, já configura uma prática de violência do Estado contra estes sujeitos; o impedimento de que ele responda pelo seu crime, uma vez configurada a 
inimputabilidade, é uma agressão psicológica ainda maior. Mesmo estabelecido o nexo causal entre o ato crime e o transtorno psíquico, considerar o sujeito incapaz de compreender esta relação e por ela responder é, de alguma forma, sentenciá-lo à própria doença e a permanecer preso a este crime pelo qual não pode pagar. Nessa medida, o dispositivo jurídico da inimputabilidade associado ao laudo de cessação de periculosidade, delegado a um perito, como única forma de revisão da medida, significa de fato a perpetuação da pena que a medida de segurança "velou" sob o artifício de uma proteção, retirando o elementar direito à defesa e o humano direito à resposta social proporcional e adequada ao ato de fato praticado. (Paulon et al., 2017, p. 362)

Além de expor a violação de direitos e as práticas violentas sofridas por esses sujeitos, a produção de um curta-metragem ${ }^{1}$ revela um pouco desse "acompanhar na rede". O audiovisual apresenta as histórias de Sandro, Wen e Fabiano, pacientes judiciários acompanhados pelo programa. Alinhado aos princípios da Reforma Psiquiátrica brasileira, profissionais, bolsistas e professores extensionistas buscavam trabalhar com os pacientes judiciários e juízes criminais pela garantia do direito ao cuidado em liberdade. A história de Fabiano, por exemplo, ex-interno de um instituto psiquiátrico forense, mostra-nos que nenhuma vida pode ser reduzida a um crime ou a uma doença. Diante do desejo de escuta, Fabiano nos conta a sua história e como chegou ao instituto psiquiátrico. 0 mesmo ocorreu com Ana, Alva e Elaine, mulheres acompanhadas por nós em seus processos de desinstitucionalização. Ao acompanhar essas e outras pessoas, tínhamos como objetivo superar as histórias únicas contadas pela psiquiatria e pelo sistema penal.

Em seus nove anos de existência, o programa Des'Medida já passou por diversas fases e vivenciou muitos impasses em seu desenvolvimento. Entre os anos de 2012 e 2013, o programa foi articulado e estruturado com parcerias dentro da universidade e com a Secretaria Estadual de Saúde e o Tribunal de Justiça, por exemplo. A viabilidade do programa sempre esteve aliada à implicação de esforços conjugados das várias entidades públicas, pactuados conforme as disponibilidades e responsabilidades de cada participante no processo: a parceria com a Superintendência de Serviços Penitenciários (SUSEPE), responsável pelo Instituto Psiquiátrico Forense, que se deve ao fato de a ação também atingir os pacientes judiciários já internalizados, tratando-se de apoio técnico-teórico; o apoio da Secretaria Municipal de Saúde em relação à garantia de articulação com a rede de saúde no município; o Tribunal de Justiça do Rio Grande do Sul (TJ-RS), responsável pelo apoio técnico-teórico; o apoio da Secretaria Estadual de Saúde no âmbito da articulação da rede de saúde nas instâncias de responsabilidade desta; o Serviço de Assessoria Jurídica Universitária (SAJU), com a parceria de assessoria jurídica através do atendimento a demandas de ordem legal visando a contrapartida da formação universitária; e o Programa de PósGraduação em Psicologia Social e Institucional da UFRGS, oferecendo apoio técnico e incentivo à produção acadêmica. Tais articulações demonstram o caráter interdisciplinar, intersetorial e a imbricação das ações de ensino, pesquisa e extensão no contexto universitário, presentes desde o início do desenvolvimento deste programa.

Nos três anos seguintes, a proposta foi contemplada com financiamentos de editais federais que existiam para estimular a extensão acadêmica - o PROEXT MEC-SESU. Com esse respaldo que viabilizou a ampliação da equipe com até 10 bolsas de extensão por ano, o programa pôde se articular aos pontos de atenção das redes de segurança, saúde e assistência das redes territoriais, acompanhando os pacientes judiciários mediante o dispositivo clínico do acompanhamento terapêutico e prestando assessorias aos juízes, com supervisões e encontros periódicos entre professores e estudantes bolsistas da Psicologia, Serviço Social e Direito. Ainda nesse período, foram realizados eventos e visitas técnicas, em parceria com o PAI-PJ, a Universidade Federal Fluminense e a Defensoria Pública do Rio de Janeiro, criando uma rede de 
pesquisadores e extensionistas unidos em prol da desinstitucionalização dos pacientes judiciários e da medida de segurança.

Com o fim dos financiamentos e escassez de recursos, desde 2016, tornou-se cada vez mais difícil a consecução de um dos objetivos fundantes que o programa carrega em seu título: o "acompanhar na rede”. Além disso, entraves burocráticos, dificuldades com os espaços físicos, conflitos de hierarquia entre duas grandes instituições públicas, impasses nas relações e acordos firmados com o Tribunal de Justiça e resistência de profissionais e equipes de saúde em relação aos processos de desinstitucionalização apresentaramse como fatores importantes na reavaliação do programa em sua frente de ações de caráter mais assistencial com a rede. Não seria inapropriado resumir algumas dessas incompatibilidades com o papel que a dogmática jurídico-penal estabelece na relação com outras formas de saber: em vez do trabalho cooperativo interdisciplinar, a forma da auxiliaridade (Carvalho, 2010). Assim, a aliança transforma-se gradualmente em serviço, assessoria pericial, tornando a posição do programa subalterna às formas jurídicas de articular as questões.

Cabe destacar que as reformulações ocorridas no programa, com o fim dos financiamentos e escassez de recursos, são um efeito micropolítico de processos macropolíticos de liberalização e desregulamentação do ensino superior, com a manifestação explícita de uma política de privatização da educação superior no país, bem como de políticas de austeridade fiscal, cujos impactos para a proteção social não são universais, atingindo as camadas mais vulneráveis da população. Sem a previsão, a formulação e a realização de políticas públicas de saúde, educação, assistência social e geração de renda, associados ao desmonte da Reforma Psiquiátrica brasileira e seus movimentos de remanicomialização, o que nos resta é o sentimento de desamparo e a necessidade de resistência. Por isso, é impossível dissociar o avanço da austeridade e da programação neoliberal do avanço neoconservador e punitivista que atravessa a conjuntura nacional, somando-se, aos esforços de desregulamentação, a apropriação do espaço público por formas de doutrinação religiosa e exploração lucrativo-privatizante do espaço social antes reservado à efetividade dos direitos sociais, como é o caso da saúde.

Diante desse contexto, entre os anos de 2017 e 2019, algumas ações ainda foram realizadas com o Tribunal de Justiça, mas o foco passou a ser os processos formativos sobre saúde mental e direitos humanos com profissionais e estudantes de diversas áreas. Vários foram os cursos de extensão ofertados no espaço da universidade dentro da temática saúde mental e direitos humanos. Embora as ações formativas, entre os anos de 2015 e 2019, tenham alcançado aproximadamente 250 pessoas (profissionais das redes, estudantes e interessados na temática), pode-se dizer que esse foi um período de latência do programa, impactado significativamente pela ausência de apoio e investimento. Somam-se aos impasses a saída e a entrada de novas pessoas da universidade na equipe, o que levou o programa à reestruturação tanto de sua natureza quanto das ações pretendidas a partir do ano de 2020. Em compensação, os acúmulos das experiências dos anos anteriores, as articulações regionais e hoje nacionais estabelecidas com parceiros responsáveis pelo debate sobre saúde mental, direitos humanos e sistema penal e a disposição teórico-militante do grupo se mantêm, configurando esforços para o enfrentamento dos novos desafios que demandam a elaboração de novas estratégias de ação.

\section{Reestruturação e ações do programa durante a pandemia}

O início de 2020 trouxe à equipe e aos novos integrantes a necessidade de propor um movimento de análise da história do programa, dos seus avanços e impasses. Parte deste relato de experiência é fruto desses encontros de avaliação e planejamento, que tiveram como um de seus pontos nodais a discussão sobre a natureza do programa e a função da própria universidade. Algumas questões nortearam esse debate: que função caberia a um programa de extensão em relação à assistência de pacientes judiciários junto da rede de serviços? Com os recursos limitados de que dispunha, como compor uma equipe que apoiasse de fato as ações desinstitucionalizantes? Como constituir-se um “dispositivo articulador de redes”, expressão extraída 
da experiência do PAI-PJ, desde uma inserção institucional externa à saúde e ao judiciário?

Mantido o propósito fundante de contribuir com a promoção do exercício da cidadania e da atenção integral ao paciente judiciário, estendendo garantias legais a uma população historicamente alijada de seus direitos, o Des'Medida foi reestruturado, com vistas a se constituir num "Núcleo de Referência de Pesquisa e Formação em Saúde Mental, Direitos Humanos e Sistema Penal”. Com ênfase, para sua continuidade, na vocação acadêmica de um programa de extensão, as ações dessa nova etapa enfocariam o objetivo de construir espaços de formação e apoio para profissionais e estudantes, com o que foram propostas as seguintes ações: (1) levantamento, sistematização e análise das experiências de extensão acadêmica e intervenções no campo da desinstitucionalização dos pacientes judiciários no Brasil; (2) formação-intervenção problematizando a aplicação das medidas de segurança no âmbito do direito penal brasileiro, referenciada nos princípios da Reforma Psiquiátrica e da criminologia crítica; (3) estruturação de um observatório de saúde mental e direitos humanos, bem como criação de um espaço de acolhimento e acompanhamento de casos de violação de direitos que envolvam violências manicomiais e descumprimento das garantias legais salvaguardadas pela Reforma Psiquiátrica brasileira.

Entretanto, a pandemia do novo coronavírus (SARS-Cov-2) e a doença provocada por ele (covid-19) nos tomou de surpresa, afetando a vida de todos e todas de um modo geral e, especificamente, transformando os meios e as formas com que desenvolveríamos as ações inicialmente propostas. Com a implantação do Ensino Remoto Emergencial (ERE) em nossa universidade, as reuniões quinzenais da equipe passaram a ocorrer de forma on-line através das plataformas digitais. Realizamos, ao longo do ano, estudos e pesquisas não-sistemáticas de artigos, dissertações, teses, livros e e-books, cartilhas, documentos, portarias, vídeos, documentários e outros materiais que versassem sobre a temática da saúde mental, direitos humanos e sistema penal. Todos esses documentos foram constituindo o escopo do que denominamos de "Observatório Saúde Mental, Direitos Humanos e Sistema Penal". ${ }^{2}$

O site do Observatório foi pensado como espaço aberto para troca de informações (com e-mail do programa e canal de comunicação próprio do site), disponibilização de materiais aos(às) interessados(as) na discussão e compartilhamento público das ações de formação-intervenção do Des'Medida. Essa ação se assemelha muito a uma das primeiras iniciativas do Observatório Nacional de Saúde Mental e Justiça Criminal da Universidade Federal Fluminense (ONSMJC/UFF), que criou uma plataforma virtual, construída no formato de banco de dados para consulta livre (Tedesco, 2018). O ONSMJC/UFF, estruturado em 2013 para fomentar o realinhamento das práticas de saúde mental à perspectiva do movimento da reforma psiquiátrica, teve como objetivo inicial "estabelecer diretrizes gerais norteadoras das políticas públicas na área da atenção à saúde mental dos indivíduos com transtorno mental em conflito com a lei" (Tedesco, 2018, p. 84).

Com objetivos semelhantes, embora com dimensões e pretensões distintas, espera-se que haja uma profícua articulação entre as duas propostas, combinando possíveis ações de formaçãointervenção. ${ }^{3}$ Mesmo que não tenhamos o contato direto com as pessoas com transtornos mentais em conflito com a lei, pretendemos, por meio da constituição do "Núcleo de Referência de Pesquisa e Formação em Saúde Mental, Sistema Penal e Direitos Humanos" e do Observatório, construir espaços de acolhimento e acompanhamento de casos de violação de direitos que envolvam violências manicomiais e descumprimento das garantias legais asseguradas pela Reforma Psiquiátrica brasileira, além de oferecer apoio a equipes de trabalhadores envolvidas com os processos de desinstitucionalização. Como nos diz Barros-Brisset (2011):

\footnotetext{
20 observatório está disponível em: <https://www.desmedidaufrgs.com/>.

3 Cabe destacar que a noção utilizada de formação-intervenção tem como inspiração as metodologias da pesquisa-intervenção, que buscam desnaturalizar constantemente o objeto que se pretende conhecer, uma pesquisa-implicada, pesquisa-inclinação que produz desvios sobre o campo investigado, nunca dissociando objeto investigado do sujeito que investiga.
} 
Basta dar a palavra a esses indivíduos ditos perigosos para perceber o que nossa experiência revela: essa engenhoca conceitual está a serviço de uma ficção, e mesmo por ser ficção não deixa de ter efeitos mortíferos ao incidir no real dos corpos e das práticas institucionais, na maioria das vezes, calando e mortificando a resposta do sujeito em sua singularidade inequívoca e impossível de prever. (Barros-Brisset, 2011, p. 49)

Na tentativa de fazer circular a palavra e as experiências com os pacientes judiciários, desenvolvemos uma ação de formação-intervenção que denominamos de Ciclo de Diálogos Des'Medidos, ${ }^{4}$ constituída por um conjunto de sete vídeos com entrevistas realizadas com membros da nossa equipe e profissionais e pesquisadores interessados no debate sobre a desinstitucionalização das medidas de segurança. Os temas das entrevistas tratam de questões e reflexões sobre o fenômeno da portagiratória (o paciente judiciário entre o Direito e a Psiquiatria), a medida de segurança na perspectiva da criminologia crítica, serviço social e processos de desinstitucionalização, os sujeitos "intratáveis" entre os sistemas penal e de saúde, a relação entre gênero, loucura e cidadania, periculosidade e as relações do Judiciário com as redes.

A concepção e a elaboração dos vídeos que compuseram o ciclo, enquanto materiais de educação permanente e de intervenção-formação, acabaram servindo de inspiração para a construção de uma proposta de um curso de extensão, direcionado a profissionais e estudantes das áreas da saúde, direito e serviço social. Textos e materiais complementares foram selecionados como recursos pedagógicos aliados aos vídeos produzidos pelo Des'Medida. Entretanto, em pleno semestre de aulas em ERE, entendemos que a oferta de mais atividades on-line, do tipo síncronas, resultaria na falta de interessados. Encontramos nas propostas de Ensino a Distância (EaD) uma alternativa interessante: os cursos livres Massive Open Online Course (MOOC).
Em primeiro lugar, cabe destacar que o EaD é uma modalidade educacional na qual a mediação dos processos de ensino e aprendizagem ocorre pela utilização de meios e tecnologias da informação e comunicação, com políticas de acesso, avaliação e acompanhamento compatíveis, e que permita aos(às) estudantes o acesso aos materiais didáticopedagógicos em diferentes tempos e espaços (Arruda, 2020). Dentro do EaD, principalmente durante o período da pandemia, destacaram-se as propostas de MOOC. 0 curso online aberto e massivo é oferecido nos Ambientes Virtuais de Aprendizagem (AVA) e visa promover a oportunidade de ampliação de conhecimentos para muitas pessoas, que podem acessar os materiais em diferentes tempos e espaços.

Será que existem indivíduos intrinsecamente perigosos? Se uma pessoa com transtorno psíquico comete algum crime, essa pessoa deve ser isolada e excluída do convívio em sociedade? Essa pessoa pode ser responsabilizada pelo crime que cometeu, por exemplo, em surto psicótico? Se ela for penalizada, deve ser com uma pena de reclusão? Sendo uma pessoa criminosa, tem direito a tratamento? E se tiver, esse tratamento é de responsabilidade do Estado, do sistema de saúde ou de segurança? Aliás, ela pode responder por um crime se for considerada uma pessoa que não tem responsabilidade sobre os seus atos? O que vocês acham de uma pessoa não ter como responder pelos seus atos? E esse crime pode ter seus efeitos justificados ou atenuados perante a Lei já que cometido por alguém com transtorno psíquico?

Essas são algumas das questões que o curso "Saúde Mental, Direitos Humanos e Sistema Penal", organizado pelo programa, propõe à discussão. Com a finalidade de criar espaços de formação que contribuam com a desinstitucionalização da medida de segurança, o curso é referenciado nos princípios da Reforma Psiquiátrica e da criminologia crítica e estrutura-se em quatro módulos teóricos no formato autoinstrucional e gratuito. Cada módulo é subsidiado por textos e vídeos que compõem o Ciclo de Diálogos Des'Medidos, entrevistas com profissionais sobre experiências e reflexões

\footnotetext{
4 Essa ação de formação-intervenção foi disponibilizada no site do Observatório e também em nossa página no YouTube, podendo ser acessada em: <https://www.youtube.com/channel/UCNl7hcRq5ypзiPiJMzelytg>.

5 Após o cadastro na Plataforma Lumina, o(a) usuário(a) pode acessar o curso pelo link: 〈https://lumina.ufrgs.br/course/view.php?id=123〉.
} 
teórico-conceituais acerca da temática do curso. Os módulos são também constituídos por fóruns de discussão entre os participantes, que contam com um documentário disparador dos debates e avaliações objetivas sobre os conteúdos. Contados oito meses desde sua publicação no portal, o curso conta com aproximadamente 3.40o pessoas inscritas e que responderam ao questionário inicial, indicando o início do curso. São participantes de todo o Brasil, sendo que mais de $75 \%$ residem fora de nosso Estado, compostos por uma maioria de mulheres, com ensino superior incompleto e completo, sem vinculação com movimentos sociais de saúde mental e direitos humanos, mas já com algum conhecimento prévio sobre as medidas de segurança. Desde dezembro de 2020, 920 pessoas já o concluíram, sendo que destes, mais de $80 \%$ avaliaram todos os itens do questionário de avaliação como muito bom ou excelente, com avaliações descritivas destacando a excelência do curso e os aprendizados adquiridos para a formação acadêmica e atuação profissional.

Para além dos números, que nos impressionaram e superaram nossas expectativas, a experiência da produção do Ciclo de Diálogos Des'Medidos e do curso no formato MOOC indicam-nos a possibilidade de maior utilização das tecnologias digitais de informação e comunicação nos processos de intervenção-formação, ampliando espaços de discussão, fortalecendo e interagindo com outros possíveis interlocutores que também acreditam e lutam pela desinstitucionalização na área da saúde mental e do sistema penal. As discussões nos fóruns desse curso vão ao encontro do pensamento de Ramos (2019), de que é preciso deslocar nossas práticas para a construção de um novo projeto de sociedade se quisermos efetivar os processos de desinstitucionalização. Como nos diz a autora:

Considerando que nossas relações de gênero se dão numa sociedade patriarcal, racista, burguesa e hegemonicamente branca, desconstruir o saber/poder da Psiquiatria e do Direito para acabar com a medida de segurança -, é também desinstitucionalizar o modo como nos relacionamos na cidade. Neste sentido, temos que "garimpar" ainda muitos caminhos, a fim de que os corpos das mulheres consigam poder atravessar. (RAMOS, 2019, p. 213)

Ressaltamos, entretanto, as potencialidades e limites de nossas ações extensionistas em tempos de pandemia. Não temos acesso a dados quantitativos de outras ações de extensão de nossa universidade para comparar com o programa aqui apresentado, mas o número de inscritos e de concluintes no curso on-line é significativo por duas razões: primeiro, porque alcançamos pessoas de todas as regiões do país, estudantes, trabalhadoras(es), interessadas(os) no tema, o que não seria possível na modalidade presencial; e, segundo, pois essa ação demonstra a necessidade de colocar na pauta da Reforma Psiquiátrica questões como a periculosidade, as medidas de segurança e a violação de direitos à qual os pacientes judiciários são submetidos cotidianamente. Foi uma das formas que encontramos para seguir resistindo e inventando possibilidades diante dos desinvestimentos e desmontes no campo da educação superior e da saúde mental, efeitos de uma suposta e proclamada crise econômica, o que legitima as políticas de austeridade. Seguimos criando ferramentas virtuais, como fóruns de discussão em grupo no site do observatório, para dar continuidade aos debates e reverberações provocados nos cursistas que concluíram o curso on-line.

Todavia, não podemos superestimar esses dados em detrimento de processos mais sutis, como os que aconteceram nos anos anteriores e que promoveram o encontro de diferentes atores em torno do estudo, da formação e da problematização das questões envolvendo saúde mental, direitos humanos e sistema penal. Os afetos e efeitos de vínculo e pertencimento a um coletivo precisam ser resgatados para os enfrentamentos que todas(os) temos diante do atual contexto político e social. "Como vai a universidade pública expor e se posicionar perante os cenários possíveis de um pós-pandemia?", questiona-se Boaventura de Sousa Santos (2021). Sem cair numa armadilha de legitimar processos de ensino e aprendizagem à distância, será preciso articular a presença física com estratégias 
de compartilhamento e articulação em redes digitais, tendo as universidades públicas o desafio de democratizar, desmercantilizar, descolonizar e despatriarcalizar (Santos, 2021).

Acreditamos que seguir promovendo o papel crítico e a função educativa da universidade, por meio de ações de intervenção-formação como as narradas neste relato, é uma das tantas formas que temos para desconstruir saberes/poderes e contribuir com o processo de desinstitucionalização da medida de segurança. Entendemos, portanto, que a manutenção do programa tem um sentido de resistência, desde a academia, contra o desmonte de políticas públicas e ataques à universidade. Nessa direção, em contraposição à formação de conformistas, cabe à extensão a formação de rebeldes competentes, como diria Boaventura de Sousa Santos (2007). Como rebeldes competentes, as ações de ensino, pesquisa e extensão no campo da saúde mental e dos direitos humanos devem seguir criando e propagando desassossegos e, se necessário, produzindo escândalos. Para que se siga produzindo escândalos e desassossegos, e para que se repolitizem globalmente as práticas sociais (Santos, 2007), pesquisar e propor ações de formação-intervenção sobre as condições dos "loucos infratores" tornam-se possibilidades concretas de dar visibilidade a mais um segmento historicamente amordaçado. Por isso, um dos nossos maiores desafios enquanto extensionistas e professoras(es) é o de "como fazer o silêncio falar de uma maneira que produza autonomia e não a reprodução de silenciamento" (Santos, 2007, p. 55).

\section{Considerações finais - por vidas $e$ corpos "des'medidos"}

Buscamos, neste relato de experiência, apresentar e refletir sobre as experiências do Des'Medida, um programa de extensão desenvolvido desde 2012 e que, em função da pandemia do novo coronavírus, teve suas propostas de ação reformuladas. Através das experiências, intentamos evidenciar problematizações sobre a medida de segurança e a noção de periculosidade, apostando em processos de desinstitucionalização da loucura. Como discutido aqui, vários foram os impasses que se apresentaram no desenvolvimento desse programa de extensão desde a sua criação, o que nos convocou a repensar e reestruturar nossas ações.

A construção do Observatório, bem como a produção do Ciclo de Diálogos Des'Medidos e do curso "Saúde Mental, Direitos Humanos e Sistema Penal", tem produzido efeitos que se desdobrarão em novas ações deste programa, dentre as quais destacamos as seguintes possibilidades: (a) rodas de conversas bimensais, que constituirão um Fórum Permanente sobre Saúde Mental, Direitos Humanos e Sistema Penal; (b) apoio a equipes dos sistemas penal e de saúde para questões da desinstitucionalização e medidas de segurança (sob demanda); (c) a produção do II Ciclo de Diálogos Des'Medidos e de um segundo curso na modalidade MOOC, a partir das sugestões dos cursistas com temas transversais às questões da periculosidade e medida de segurança, tais como os atravessamentos de gênero, classe e raça e a necropolítica no contexto da saúde mental e sistema penal.

A pandemia mudou temporariamente, e talvez definitivamente, a forma como nos relacionamos com a cidade. Mas não transformou, se não ampliou, as desigualdades e injustiças sociais. Ela gerou outras questões fundamentais no campo da saúde mental, inclusive para aqueles e aquelas que se encontram reclusos e distanciados socialmente antes mesmo do coronavírus. O Des'Medida teve que se reinventar nesse período, mas continua garimpando caminhos para que os corpos dos(as) pacientes judiciários, mulheres, negros e negras, consigam atravessar e circular pelas cidades, vacinados(as) e protegidos(as) por políticas públicas que garantam seus direitos e uma vida digna. Vidas cujo valor não cabem em medidas epidemiológicas nem se resumem àquilo que governos voltados para a morte querem delas fazer. Vidas e corpos des'medidos.

\section{Referências}

ARRUDA, E. P. Educação remota emergencial: elementos para políticas públicas na educação brasileira em tempos de Covid-19. EmRede Revista de Educação a Distância, Porto Alegre, v. 7, n. 1, p. 257-275, 2020.

AZEVEDO, C. M. M. Onda negra medo branco: o negro no imaginário das elites do século XIX. Rio de Janeiro: Paz e Terra, 1987. 
BARROS-BRISSET, F. O. Um dispositivo conector: relato da experiência do PAI-PJ/TJMG, uma política de atenção integral ao louco infrator, em Belo Horizonte. Revista Brasileira de Crescimento e Desenvolvimento Humano, São Paulo, v. 20, n. 1, p. 116-128, 2010. DOI: 10.7322/jhgd.19951

BARROS-BRISSET, F. O. Genealogia do conceito de periculosidade. Responsabilidades, Belo Horizonte, v. 1, n. 1, p. 37-52, 2011.

BRASIL. Ministério da Saúde. Nota Técnica $n^{0}$ 11/2019. Brasília, DF: 2019. Disponível em: <https://pbpd.org.br/wp-content/ uploads/2019/o2/o656ad6e.pdf >. Acesso em: 13 out. 2021.

BRASIL. Presidência da República. Lei 10.216, de 6 de abril de 2001. Dispõe sobre a proteção e os direitos das pessoas portadoras de transtornos mentais e redireciona o modelo assistencial em saúde mental. Diário Oficial da União, seção 1, Brasília, DF: 9 abr. 2001.

BRASIL. Resolução n. 4. Dispõe sobre as diretrizes nacionais de atenção aos pacientes judiciários e execução da medida de segurança. Diário Oficial da União, seção 1, Brasília, DF: 2 ago. 2010.

BRASIL. Portaria ${ }^{\circ} 94$, de $1^{\circ}$ de abril de 2014. Institui o serviço de avaliação e acompanhamento de medidas terapêuticas aplicáveis à pessoa com transtorno mental em conflito com a Lei, no âmbito do Sistema Único de Saúde (SUS). Diário Oficial da União, seção 1, Brasília, DF: 3 abr. 2014.

CARRARA, S. Crime e loucura: o aparecimento do manicômio judiciário na passagem do século. Rio de Janeiro: EdUERJ; São Paulo: EdUSP, 1998.

CARVALHO, S. Antimanual de criminologia. Rio de Janeiro: Lumen Juris, 2010.

CFP - CONSELHO FEDERAL DE PSICOLOGIA. CNS: Ministério da Saúde deve retomar serviço destinado à pessoa com transtorno mental em conflito com a lei. Brasília, 2020a. Disponível em: <https://site.cfp.org.br/cns-ministerio-dasaude-deve-retomar-servico-destinado-a-pessoacom-transtorno-mental-em-conflito-com-a-lei/>. Acesso em: 13 out. 2021.
CFP - CONSELHO FEDERAL DE PSICOLOGIA. CFP destaca posicionamento sobre extinção da Psicologia na política de atenção às pessoas privadas de liberdade. Brasília, 202ob. Disponível em: <https://site.cfp.org.br/cfp-destacaposicionamento-sobre-extincao-da-psicologiana-politica-de-atencao-as-pessoas-privadas-deliberdade/>. Acesso em: 13 out. 2021.

CORREIA, L. C. "A minha áurea não é indefesa”: Manicomialização do Sistema de Justiça e as mulheres em sofrimento mental em conflito com a lei na Paraíba. p. 153-169. In: PEREIRA, M. O. et al. (Org.). Luta Antimanicomial e Feminismos: formação e militâncias. Rio de Janeiro: Editora Autografia, 2020.

DINIZ, D. A custódia e o tratamento psiquiátrico no Brasil - Censo 2011. Brasília, DF: Editora UNB, 2013. FOUCAULT, M. Vigiar e Punir. História da violência nas prisões. Petrópolis: Vozes, 1991.

FOUCAULT, M. A evolução da noção de indivíduo perigoso na psiquiatria legal do século XIX(1977). In: FOUCAULT, M. Ética, sexualidade e política. MOTTA, M. B. (Org.). Rio de Janeiro: Forense Universitária, 2004.

MAGNO, P. C. Periculosidade, Crime e Loucura: funções do racismo no manicômio judiciário. (pp. 172-193). In: MAGNO, P. C.; PASSOS, R. G. (Org.). Direitos humanos, saúde mental e racismo: diálogos à luz do pensamento de Frantz Fanon. Rio de Janeiro: Defensoria Pública do Estado do Rio de Janeiro, 2020.

MARTINS, P. Nota técnica critica extinção do serviço a presos com transtornos mentais feita pelo Ministério da Saúde. Rio de Janeiro: Associação Brasileira de Saúde Coletiva, 2020. Disponível em: <https://www.abrasco.org.br/site/noticias/ nota-tecnica-critica-extincao-do-servico-a-presoscom-transtornos-mentais-feita-pelo-ministerio-dasaude/49133/>. Acesso em: 13 out. 2021.

PAULON, S. M.; PINTO NETO, M.; DIAS, M. T.; GUIMARAES, W. Desinstitucionalização nos manicômios judiciários: quem se assegura com a medida de segurança? In: OLIVEIRA, W. F.; PITTA, 
A. M. F.; AMARANTE, P. (Org.). Direitos Humanos \& Saúde Mental. São Paulo: Hucitec, 2017. p. 352-376.

RAMOS, B. G. M. O. O Debate sobre Raça, Gênero e Classe para as propostas em Saúde Mental na Justiça Criminal: apontamentos e entraves. In: PEREIRA, M. O.; PASSOS, R. G. (Org.). Luta Antimanicomial e Feminismos: inquietações e resistências. Rio de Janeiro: Editora Autografia, 2019. p. 205-216.

SANTOS, B. S. Renovar a teoria crítica e reinventar a emancipação social. São Paulo: Boitempo, 2007.

SANTOS, B. S. O futuro começa agora: da pandemia à utopia. São Paulo: Boitempo, 2021.

SILVA, H. C. Reforma Psiquiátrica nas medidas de segurança: a experiência goiana do PAILI. Rev Bras
Crescimento Desenvolvimento Humano, São Paulo, v. 20, n. 1, p. 112-115, 2010. DOI: 10.7322/jhgd.19950

SOARES FILHO, M. M.; BUENO, P. M. M. G. Direito à saúde mental no sistema prisional: reflexões sobre o processo de desinstitucionalização dos HCTP. Ciência \& Saúde Coletiva, Rio de Janeiro, v. 21, n. 7, p. 2101-2110, 2016. DOI: 10.1590/141381232015217.08802016

TEDESCO, S. Repensando as políticas públicas na interface entre saúde, justiça e direitos. In: MIRANDA, A. E.; RANGEL, C.; COSTA-MOURA, R. Questões sobre direitos humanos: justiça, saúde e meio ambiente. Vitória: UFES, 2018. p. 84-101.

ZAFFARONI, E. R.; BATISTA, N.; ALAGIA, A.; SLOKAR, A. Direito penal brasileiro. Rio de Janeiro: Revan, 2003.

\section{Contribuições dos autores}

Todos os autores são responsáveis pela redação deste Relato de Experiência. Romanini e Paulon coordenam o Programa de Extensão que gerou a experiência narrada e estruturaram a linha argumentativa do texto. Pasche e Pinto Neto participaram igualmente das atividades narradas e contribuíram com a revisão bibliográfica, análise dos conteúdos. Pinto Neto revisou a argumentação jurídica. Os quatro autores elaboraram conjuntamente as conclusões.

Recebido: 23/08/2021

Reapresentado: 23/08/2021

Aprovado: 27/09/2021 